\title{
Pattern alternation: Effects of spatial frequency and rientation
}

\author{
FREDERICK L. KITTERLE, RUSSELL S. KAYE, and HEATHER NIXON
}

\author{
The University of Toledo, Toledo, Ohio 43606
}

\begin{abstract}
Campbell and Howell (1972) reported an effect called "monocular pattern alternation." They found that a pattern composed of two orthogonal sinusoidal gratings, one horizontal and the other vertical, underwent rivalry when viewed monocularly for a period of time. In the present study, it has been shown that monocular pattern alternation depends upon the orientation of the pattern and the spatial frequency of its components. Fewer reversals were found for an obliquely oriented pattern than for a pattern with components in the horizontal and vertical meridians. Alternation rate was higher when the gratings were similar in frequency but differed in orientation than when the components of the pattern differed in both dimensions. It was concluded that pattern alternation reflects an antagonistic interaction between interdependent channels in the human visual system that respond to orientation and spatial frequency.
\end{abstract}

Recently, various investigators have reported an effect called monocular pattern alternation (Campbell \& Howell, 1972; Rauschecker, Campbell, \& Atkinson, 1973). When two sinusoidal gratings of similar spatial frequency are optically superimposed such that one is vertical and the other horizontal, the appearance of the pattern changes; one grating appears clearer than the other, then the situation reverses. At no time do both gratings disappear; in other words, the pattern appears to alternate. The rate of alternation depends upon several factors: the relative orientation (Campbell \& Howell, 1972), the spatial frequencies (Campbell \& Howell, 1972), and the colors of the two gratings (Rauschecker et al, 1973).

When the two gratings were both vertical, superimposed in-phase or $180 \mathrm{deg}$ out of phase, the pattern remained stationary. However, alternation was found when one of the gratings was tilted at least \pm 15 deg relative to the vertical grating. Alternation was also found if orientation was held constant and the spatial frequency of one grating differed from the other by \pm 1 octave. The rate of alternation depended upon the colors of the gratings. The rate of alternation was greater if the two gratings were complimentary in color (e.g., one red and the other green) (Rauschecker et al, 1973).

Psychophysical experiments utilizing a selective adaptation paradigm have found within the human visual cortex channels that are size- and orientation-tuned (Blakemore \& Sutton, 1969; Campbell \& Kulikowski, 1966). The tuning characteristics of these channels were $\pm 15 \mathrm{deg}$ for orientation and \pm 1 octave for size. Since a difference of either magnitude is needed for alternation to occur, it may be that pattern alternation reflects the antagonistic interaction between two or more channels within the human visual system. The purpose of the experiments reported in this paper is to provide more information about the characteristics of these channels.

\section{EXPERIMENT I}

A number of experiments indicate that visual channels seem to respond more strongly to stimuli presented in the horizontal and vertical meridians than to stimuli presented in the oblique meridians (see Appelle, 1972, for a review of the literature on the "oblique effect"). If pattern alternation involves the interaction of these visual channels, it might be that weaker antagonistic interactions would obtain between the oblique channels than between the horizontal and vertical channels. Consequently, an obliquely oriented pattern would produce fewer reversals than a horizontal-vertical pattern. This hypothesis was tested in Experiment $I$ and was confirmed.

\section{Method}

Subjects. Fourteen introductory psychology students served as Ss in this experiment for course credit. They were naive about the purpose of this investigation and were provided feedback about the nature of the investigation at its completion. All Ss had normal or corrected-to-normal vision.

Apparatus. The stimuli were presented in a three-channel Scientific Prototype tachistoscope (Model GB). Two channels were fitted with holders capable of varying the orientation of the stimuli; the blank channel functioned as an adapting field. The stimuli were photographic transparencies of sine-wave gratings generated on the face of a Tektronix 561-B oscilloscope with a P-31 phosphor. The transparencies were scanned with a photomultiplier tube to insure that they were sinusoidal and free of distortion. At a viewing distance of $106.68 \mathrm{~cm}$, the spatial frequencies of the gratings were $2.5,3.62,5.12,7.25$, and $11.60 \mathrm{cycles} / \mathrm{deg}$. The stimuli were transilluminated by the lamps of the tachistoscope. The contrast of 
the gratings (maximum luminance -- minimum luminance)/(maximum luminance + minimum luminance) was $60 \%$. The adapting field luminance and the space average luminance of the gratings was $0.3 \log \mathrm{fL}$ measured with an S.E.I. photometer. The apparatus was located in a sound proof, dimly lit room.

Procedure. Ss were assigned randomly to one of two experimental conditions of seven $\mathrm{Ss}$ each. In one condition, each slide was placed in a separate channel and oriented at 45 and $135 \mathrm{deg}$, respectively, forming an $X$ pattern (called the oblique-oblique or $\mathrm{O}-\mathrm{O}$ condition). In the other condition, a cross was formed by optically superimposing horizontal and vertical gratings (this condition was called the horizontal-vertical or $\mathrm{H}-\mathrm{V}$ condition). There were five palterns consisting of the different spatial frequencies for each condition. Each pattern was judged 10 times, making a total of 50 trials per S. One grating was red, the orthogonal one, green. These colors were produced by Wratten filters No. 33 and No. 61.

At the beginning of the experimental session, the $S$ dark-adapted for $5 \mathrm{~min}$ and then light-adapted to the $0.3 \log \mathrm{fL}$ field. During this time, the instructions were read. Ss were told to report each time the pattern alternated during a $60-\mathrm{sec}$ viewing period. A trial consisted of a ready period followed by the offset of the adapting ficld and the presentation of the pattern for $60 \mathrm{sec}$, after which the pattern was extinguished and the adapting tield turned on again. Five scconds intervened before the next trial.

\section{Results}

The results of this experiment are summarized in Fig. 1, where the number of alternations is plotted as a function of spatial frequency for the $\mathrm{O}-\mathrm{O}$ and $\mathrm{H}-\mathrm{V}$ conditions. Each data point is the mean of the median judgments for the seven $\mathrm{Ss}$. These results were subjected to an analysis of variance.

The fact that the $\mathrm{H}-\mathrm{V}$ curve is above the $\mathrm{O}-\mathrm{O}$ curve in Fig. 1 indicates that there were significantly more alternations per minute for the former group than for the latter $[F(1,12)=27.96, p<.001]$. The number of reversals also depends upon the spatial frequency of the pattern. There were significantly fewer reversals for both the higher and lower spatial frequencies in both conditions $[F(4,60)=4.52, p<.005]$. The number of alternations was an inverted $U$-shaped function of spatial frequency.

\section{EXPERIMENT II}

Recently, Atkinson, Campbell, Fiorentini, and Maffei (1973) investigated monocular pattern alternation as a function of spatial frequency for a range of frequencies from 1 to 15 cycles/deg. In Fig. 3 of their study, an inverted U-shaped function relating pattern alternation to spatial frequency was graphed. However, Atkinson et al (1973) argued that these curves were due to an artifact resulting from a difference in contrast for the 3-cycle/deg grating in their study. According to them (see their Fig. 1), pattern alternation monotonically decreases with an increase in spatial frequency.

The explanation of the inverted U-shaped curve as an artifact cannot account for the data presented in Fig. 1 of the present study, since contrast was constant over the low spatial frequency range. Perhaps the difference in functions between the two

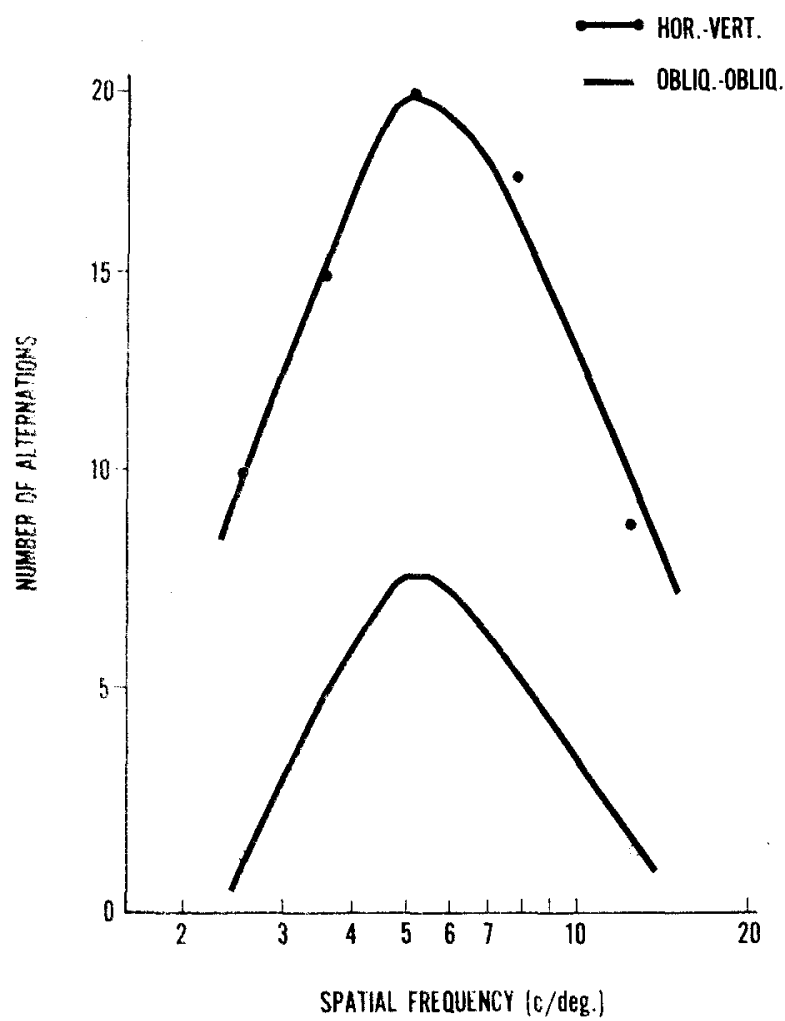

Fig. 1. The results of Experiment I. Number of alternations are plotted as a function of spatial frequency for two conditions of stimulus presentation $\mathbf{0 . O}$ and $\mathrm{H}-\mathrm{V}$. Each data point is the mean of the median judgment of seven Ss.

studies was due to differences in Ss. In Experiment I of the present study, a large number of inexperienced Ss were used, while in the Atkinson et al (1973) experiments a small number of highly experienced $S$ s participated. In order possibly to clarify the differences in results between the two studies and determine the form of the function for low spatial trequencies, Experiment II was run.

\section{Method}

Subjects. Four graduate students, familiar with the phenomenon of pattern alternation but naive with respect to the purpose of the experiment, served as Ss. All had normal or corrected-to-normal vision.

Procedure. The procedure in this experiment was similar to that of Experiment I. Ss judged the number of alternations per minute for an $\mathrm{H} \cdot \mathrm{V}$ pattern whose components frequencies were $0.6,0.8$, 1.5 , and 2.0 cycles $/ \mathrm{deg}$. The contrast of each grating was constant $860 \%$, and the space average luminance (maximum luminance + minimum luminance) $/ 2$ was $0.3 \log \mathrm{fL}$. Each pattern was judged four times for a total of 16 trials per $S$.

\section{Results}

The results of this experiment are presented in Table 1. In this table, the average judgment over Ss is presented for each spatial frequency. The results indicate that alternations increase with spatial frequency $[F(3,9)=5.15, p<.025]$. 
Table 1

Number of Alternations Per Minute as a Function of Spatial Frequency (Cycles/Degree) for Experiment II

\begin{tabular}{ccc}
\hline S & $\begin{array}{c}\text { Spatial } \\
\text { Frequency }\end{array}$ & $\begin{array}{c}\text { Alternations } \\
\text { Per Min }\end{array}$ \\
\hline & 0.6 & 53.8 \\
G. E. F. & 0.8 & 65.8 \\
& 1.5 & 71.3 \\
& 2.0 & 88.0 \\
P. A. D. & 0.6 & 21.0 \\
& 0.8 & 24.5 \\
& 1.5 & 30.5 \\
T. J. Mc. & 2.0 & 33.3 \\
& 0.6 & 20.0 \\
& 0.8 & 22.5 \\
& 1.5 & 30.0 \\
J. A. R. & 2.0 & 20.5 \\
& 0.6 & 10.3 \\
& 0.8 & 33.5 \\
& 1.5 & 37.5 \\
\hline
\end{tabular}

\section{DISCUSSION}

Both Experiments I and II indicate fewer reversals for the gratings of low spatial frequency, but the number of reversals is much greater in Experiment II. Since the periods of dominance and suppression are not always clear-cut, naive Ss may have reported only reversals when period of dominance and suppression are clear-cut. A post experimental interview with some of the Ss tends to support this contention. The more sophisticated Ss in Experiment II were aware of the subtle changes in the appearance of the two orthogonal orientations and hence reported more reversals in the pattern. Both groups, however, were clearly instructed that the changes may not always be clear-cut. There is no indication that the bias in reporting reversals varied systematically with spatial frequency.

In summary, pattern alternation seems to be an inverted $\mathrm{U}$-shaped function of spatial frequency.

\section{EXPERIMENT III}

It has been suggested that independent channels in the human visual system respond to stimulus orientation and size. Campbell and Howell (1972) have pointed out that pattern alternation indicates that these channels interact. Experiment III was run in order to determine the nature of the interaction between orientation and spatial frequency channels.

\section{Method}

Subjects. Fourteen Ss with normal or corrected-to-normal vision participated in this experiment for course credit in introductory psychology and had not participated in the previous experiments. All were naive about the purpose of the experiment.
Apparatus and Procedure. The apparatus and stimuli for this experiment were similar to those used in the previous experiments. The adaptation procedure and the instructions were similar to those in Experiment I; however, in this experiment, the spatial frequency of one grating was held constant at $5.12 \mathrm{cycles} / \mathrm{deg}$ and the orthogonal grating had the same spatial frequency or was $2.5,3.62$, 7.25 , or 11.60 cycles $/ \mathrm{deg}$. There were two conditions of seven Ss each, an $\mathrm{O}-\mathrm{O}$ and an $\mathrm{H} \cdot \mathrm{V}$ condition.

The rest of the procedure was the same as that of Experiment I (i.e., 60 -sec viewing period and 10 judgments per pattern).

\section{Results}

The results of this experiment are presented in Fig. 2. Each data point in this figure is the mean of the median judgments for the seven Ss in each condition. In this figure, the number of alternations is plotted as a function of the spatial frequency of the second grating. The orthogonal grating had a constant spatial frequency of $5.12 \mathrm{cycles} / \mathrm{deg}$. There were significantly fewer reversals for the $\mathrm{O}-\mathrm{O}$ condition than for the H-V condition $[F(1,12)=21.9$, $\mathrm{p}<.001]$, as in Experiment I.

There were significantly fewer reversals when the spatial frequencies of the two gratings differed; that is, spatial frequency had a significant effect $[F(4,60)$ $=6.07, \mathrm{p}<.001]$. The number of alternations was an inverted $U$-shaped function of spatial frequency. The effects of spatial frequency were not similar for

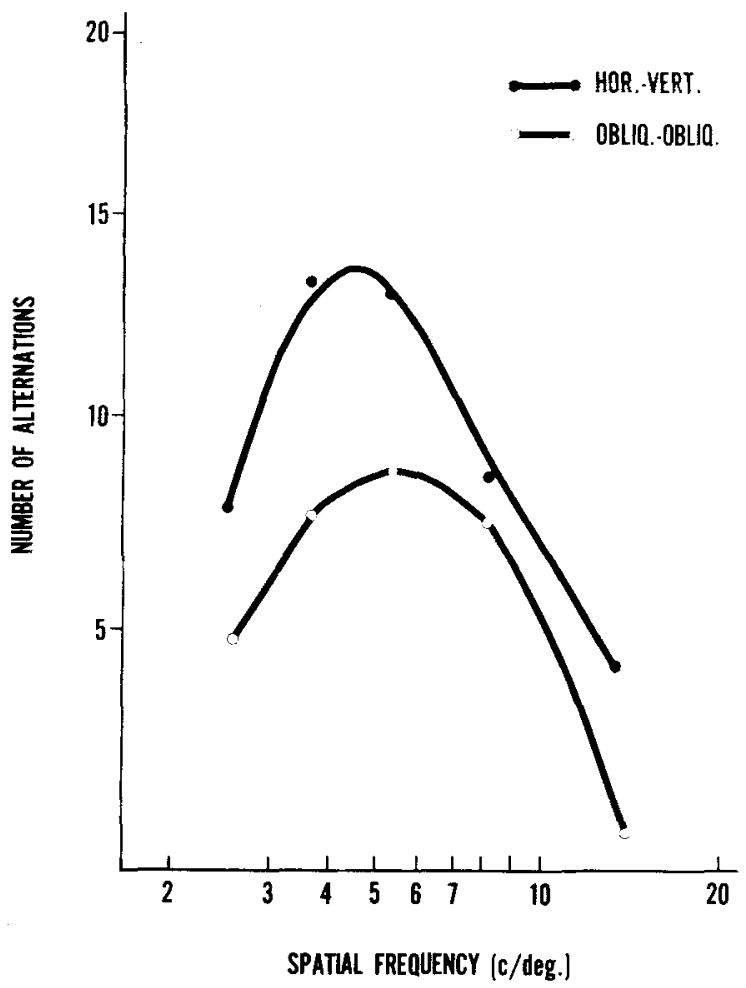

Fig. 2. Results of Experiment II. Number of altemations for H-V and 0.0 patterns are plotted as a function of the spatial frequency of the horizontal grating. The vertical grating was constant, 5.12 cycles/deg. Each data point is the mean of the median judgment of seven Ss. 
the two conditions of pattern presentation. As can be seen in this figure, the $\mathrm{O}-\mathrm{O}$ curve is broader than the $\mathrm{H}-\mathrm{V}$ curve. That is, spatial frequency interacts significantly with pattern orientation $[\mathrm{F}(4,60)=2.87$, $\mathrm{p}<.05]$.

\section{GENERAL DISCUSSION}

In the present study, it was shown that pattern alternations resulting from interactions between these channels are much greater when the $\mathrm{H}-\mathrm{V}$ channels are involved than when $\mathrm{O}-\mathrm{O}$ channels are involved. Since oblique channels may be either fewer in number or less sensitive than $\mathrm{H}-\mathrm{V}$ channels, their interaction should be weaker, and hence if pattern alternation depends upon interactions among these channels it should be less when oblique channels are involved. Other studies, Campbell and Howell (1972) and Campbell, Gilinsky, Howell, Riggs, and Atkinson (1973) suggest that monocular rivalry depends upon properties of orientation-selective units.

Spatial frequency also plays a role in pattern alternation. The low spatial frequency roll-off on the inverted U-shaped function found in Experiment I and the results of Experiment II for spatial frequencies less than 2 cycles/deg may be due to the fact that channels in this region are more sensitive to motion than to form (Tolhurst, 1973). Consequently, the interaction of these channels to stationary gratings might be weaker and result in fewer reversals.

The processing of spatial frequency, however, depends upon pattern orientation. Specifically, for two orthogonal gratings, pattern reversals were greatest when the spatial frequencies of the gratings were similar. As the spatial frequency of one of the gratings changed, pattern alternation decreased. This result seems to indicate that channels sensitive to orientation and spatial frequency may not be independent. A similar conclusion can be reached upon examination of Figs. 2 and 5 of Campbell and Kulikowski (1966), where the shape of the contrast-sensitivity curves were found to depend upon grating orientation.
The tuning characteristics of oblique detectors were shown to be broader than those detectors responding to vertically or horizontally oriented stimuli (Campbell \& Kulikowski, 1966). In Experiment III of the present study, there was an interaction between pattern orientation and spatial frequency. The curve for the $\mathrm{O}-\mathrm{O}$ condition was broader than the $\mathrm{H}-\mathrm{V}$ curve. This result is also consistent with the hypothesis that spatial frequency analysis is not independent of orientation.

In summary, monocular pattern alternation provides another method for investigating the organization of human visual channels. In this investigation, it was shown that channels responding to orientation and spatial frequency are not independent. Spatial frequency analysis depends upon orientation. It was suggested that the decrease in pattern alternations for low spatial frequencies reflects the operation of motion-detecting channels.

\section{REFERENCES}

Appelle, S. Perception and discrimination as a function of stimulus orientation: The "oblique effect" in man and animals. Pspchological Bulletin, 1972, 78, 266-278.

Atkinson, J., Campbell, F. W., Fiorentini, A., \& Maffei, L. The dependence of monocular rivalry on spatial frequency. Percepion, 1973, 2, 127-133.

Blakemore, C. C., \& Sutron, P. Size adaptation: A new aftcr effect. Scicnce, 1969, 166. 245-247.

Campbell, F. W.. Gilinsky, A. S., Howell, E. R., Riggs, L. A., $\&$ ATKINSON, J. The dependence of monocular rivalry on orientation. Perception, 1973, 2, 123-125.

CAmpbell, F. W., \& Howell, E. R. A method for investigating pattern vision. Joumal of Physiology, 1972, 210, 19-20 P.

Campbell, F. W., \& KulikowsKi, J. J. Orientation selectivity of the human visual system. Joumal of Physiology, 1966, 187. 437-445.

Rauschecker, J. P. J., Campbell, F. W., \& Atkinson, J. Color opponent neurons in the human visual system. Nature, $1973,245,42-43$.

Tolmurst, D. J. Separate channeis for the analysis of the shape and the movement of a moving visual stimulus. Journal of Physiology, 1973, 231, 385-402.

(Received for publication December 24, 1973; revision received July 15,1974 .) 